\title{
In vitro Interaction of Metronidazole and Mebendazole with Copper (II) and Chromium (III) in Aqueous Media
}

\author{
F. Siraji ${ }^{1}$, A. T. M. Z. Azam¹, M. S. Amran' ${ }^{1}$ J. N. Islam², F. M. Amjad ${ }^{3}$, and M. A. Hossain ${ }^{*}$ \\ ${ }^{1}$ Department of Pharmaceutical Chemistry, Faculty of Pharmacy, University of Dhaka, Dhaka-1000, \\ Bangladesh \\ ${ }^{2}$ Research Center for Mathematical and Physical Sciences, University of Chittagong, Chittagong, \\ Bangladesh \\ ${ }^{3}$ Department of Surgery, Dhaka Medical College Hospital, Dhaka-1000, Bangladesh
}

Received 10 May 2011, accepted in final revised form 9 December 2011

\begin{abstract}
The interaction of metronidazole, an antiprotozoal agent and mebendazole, an important anthelmentic agent with $\mathrm{Cu}$ (II) and $\mathrm{Cr}$ (III) ions have been studied in aqueous systems at a fixed temperature of $37 \pm 0.5^{\circ} \mathrm{C}$ and at different $\mathrm{pH}$ values. It has been found that metronidazole and mebendazole form stable 1:1 complexes with $\mathrm{Cu}(\mathrm{II})$, but a less stable complex with $\mathrm{Cr}(\mathrm{III})$ ion. The studies were performed by electroanalytical and spectrophotometric methods. Spectral studies helped to detect initial complexation between the species. Conductometric titration indicated the nature of interaction and the stoichiometries of complexation. The conductometric study also indicated the formation of complexes of various molar ratios viz 1:2, 4:1, 3:1, 1:2, 1:3 and 1:4. etc. along with 1:1 complexes at various $\mathrm{pH}$ conditions. Similar types of complexation were observed by Job's plots at various $\mathrm{pH}$ values. The Ardon's spectroscopic method confirmed the 1:1 complexation and the values of stability constant were calculated using Ardon's plot. Complexation at molar ratios 1:3 and 1:4 can not be ruled out.
\end{abstract}

Keywords: Metronidazole; Mebendazole; Cu(II); Cr(III); Ardon’s plot; Complexation. (C) 2012 JSR Publications. ISSN: 2070-0237 (Print); 2070-0245 (Online). All rights reserved. doi: $10.3329 /$ jsr.v4i1.7599

J. Sci. Res. 4 (1), 173-181 (2012)

\section{Introduction}

The study on interaction and complexation of drug molecules with other drugs species and various metal ions is an important field of research in the chemical, biochemical and medicinal point of views [1,2]. Binding and complexation of drug molecules and medicinal substances with metal ions and other species remarkably influence the bioavailabilities and biochemical properties of drugs in our body. Our body possesses a large number of metals to operate its normal physiological activities. We also intake a

*Corresponding author: arshi15du@yahoo.com, zafrulazam@yahoo.com 
number of metals in the dosage forms, diet, drinks and other ways and they come in close contact with different drugs and biomolecules present in the dietary and body systems. Drug interaction followed by complexation with metal ions results from donor-acceptor mechanism or Lewis acid-base reaction between two or more different chemical entities or medicinal agents [3-5]. Accordingly, Haider and co-workers [6] investigated the complexation of thiamine (vitamine $\mathrm{B}_{1}$ )- $\mathrm{HCl}$ with $\mathrm{Co}(\mathrm{II}), \mathrm{Cu}(\mathrm{II}), \mathrm{Zn}(\mathrm{II}), \mathrm{Cd}(\mathrm{II})$ and $\mathrm{Mg}(\mathrm{II})$ in the aqueous $\mathrm{MeOH}$ media. Meanwhile, we have studied the complexation of barbitone with $\mathrm{Cd}(\mathrm{II}), \mathrm{Ni}(\mathrm{II})$ and $\mathrm{Cr}(\mathrm{III})$, of dopamine and diphenyl carbazide with $\mathrm{Cu}(\mathrm{II})$ and $\mathrm{Zn}(\mathrm{II})$ and complexation of similar other molecules with metal ions in the aqueous and mixed media under varying conditions [7-12]. In our continuing studies to find out the interactions of other drugs molecules with metals ions, here we report the interaction of metronidazole, an antiprotozoal agent [13] and mebendazole, an important anthelmentic agent [13] with $\mathrm{Cu}(\mathrm{II})$ and $\mathrm{Cr}(\mathrm{III})$ ions.

\section{Experimental}

\subsection{Materials}

Metronidazole and mebendazole (product grade) have been obtained from the manufacturer, Drug International, Dhaka, Bangladesh for this study. Copper (II) chloride and chromium (III) chloride were used in this study without further purification. Potassium dihydrogen phosphate, disodium hydrogen phosphate, potassium chloride (analytical grade, BDH, England), hydrochloric acid (AR, China), acetic acid (90\%), ethanol ((analytical grade, MERK, Germany) have been used without further purification. Deionized water was used for preparation of working solutions.

\subsection{Equipments}

UV-Visible Spectrometer (UV - 1601, Shimadzu, Japan), pH meter (Mettler Toledo, Switzerland), conductometer (Mettler Toledo, Switzerland), power sonic (Model No. 510, Seoul, Korea) have been utilized in this study.

\subsection{Methods}

The in vitro interaction study of metronidazole and mebendazole with $\mathrm{Cu}(\mathrm{II})$ and $\mathrm{Cr}$ (III) ions has been studied by observing absorption spectra, conductometric data, Job's continuous vatiation [14] and Ardon's spectrophotometric methods [15].

\subsection{Spectrophotometric analysis}

The initial detection of complex formation of metronidazole and mebendazole with $\mathrm{Cu}$ (II) and $\mathrm{Cr}(\mathrm{III})$ ions was accomplished by comparing the absorption spectra of pure 
compounds and their 1:1 mixtures in buffer solutions at $\mathrm{pH} 0.8,1.4,2.4,6.4$ and 7.4. The concentrations of the samples were kept at very dilute levels in each case and the measurements of the spectra of pure sample as well as their mixtures were made using UV-VIS automatic recording instrument with a constant temperature cell compartment.

Conductometric titration in demineralized system at different pHs were carried out to find out the molar ratios of metronidazole and mebendazole with $\mathrm{Cu}$ (II) and $\mathrm{Cr}(\mathrm{III})$ at which complexation occurred. Here, $40 \mathrm{ml}$ of $5 \times 10^{-3} \mathrm{M}$ metronidazole or mebendazole solution was taken in a $100 \mathrm{~mL}$ beaker and titrated with gradual addition of $5 \times 10^{-2} \mathrm{M}$ solution of $\mathrm{Cu}(\mathrm{II})$ or $\mathrm{Cr}(\mathrm{III})$ from a burette. Reversely $40 \mathrm{~mL}$ each of $5 \times 10^{-3} \mathrm{M}$ solution of $\mathrm{Cu}$ (II) or $\mathrm{Cr}(\mathrm{III})$ was titrated with gradual addition of $5 \times 10^{-2} \mathrm{M}$ metronidazole or mebendazole solution under similar conditions.

The conductance values (ms or $\mu$ s) were plotted against molar ratios of the conducting species in the system. The titration curves showed breaks at the points of possible interaction. All the titrations were performed with solutions adjusted to $\mathrm{pH} 0.8,1.4,2.4$, 6.4 and 7.4 using a $\mathrm{pH}$ meter.

In Job's spectrophotometric method of continuous-variation, absorbances of series of metro.-Cu(II), metro.-Cr(III) mixtures with various molar ratios at $\mathrm{pH} 0.8,1.4,2.4,6.4$ and 7.4 were measured at $277 \mathrm{~nm}$ (for lower $\mathrm{pH}$ ) and at $328 \mathrm{~nm}$ (for higher $\mathrm{pH}$ ) by keeping the total moles constant in the mixture. Similar experiments were performed for meben.-Cu(II) and meben.-Cr(III) mixtures at $\mathrm{pH} 0.8,1.4,2.4$ and the absorbances of these systems were measured at $290 \mathrm{~nm}$. The observed absorbances of the mixtures at various mole fractions were subtracted from the sum of the values for free drug and free ligand under the same conditions. The absorbance differences (D) were then plotted against the mole fractions of drugs in the mixtures. A curve, thus obtained, showed a maximum at a point, which indicates the molar ratios of drug to ligand in the complex.

In the Ardon's Spectrophotometric method, concentrations of metronidazole and mebendazole were varied while the concentrations of the metal was kept fixed $\left(2 \times 10^{-4}\right.$ $\mathrm{M})$. The absorbance of free metronidazole solutions having $\mathrm{pH} 0.8,1.4$ and 2.4 were measured at $277 \mathrm{~nm}$ and solutions having $\mathrm{pH} 6.4$ and 7.4 were measured at $328 \mathrm{~nm}$ using UV-VIS recording spectrophotometer. Similarly, the absorbance of free mebendazole solutions having $\mathrm{pH}$ 0.8, 1.4 and 2.4 were measured at $290 \mathrm{~nm}$. For calculations, the Ardon's equation was used. This equation is given below :

$$
1 /\left(D-E_{A} C\right)=1 / K C\left(E_{\text {com }}-E_{A}\right)[B]^{\mathrm{n}}+1 / C\left(E_{\text {com }}-E_{A}\right)
$$

where,

$D=$ absorbance of mixture,

$C=$ molar concentration of the drug,

$B=$ molar concentration of the metal,

$E_{\text {com }}=$ molar extinction co-efficient of the complex, and

$E_{\mathrm{A}}=$ molar extinction co-efficient of the drug. 
The value of $n$ was chosen as 1 , which is an essential condition for validation of the method. The value for $1 /\left(D-E_{\mathrm{A}} C\right)$ was plotted versus $1 /[C]$ to get the straight lines. The concentrations of $\mathrm{Cu}(\mathrm{II})$ and $\mathrm{Cr}(\mathrm{II})$ were kept constant at $2 \times 10^{-4} \mathrm{M}$ (denoted by $B$ in the equation) and the concentration of interacting species (metro. and meben.) was varied (denoted by $C$ in the equation). The 1:1 complex gave a straight line in the plots with an intercept and a slope. The stability constant of the complex was given by-

$$
K=\text { intercept /slope }
$$

It should be mentioned that this method is valid only for the systems where 1:1 complexes are found.

\subsection{Statistical analysis}

The results were expressed as mean \pm S.E.M. values for each experiment. Differences in mean values between experimental groups were analyzed by unpaired ' $\mathrm{t}$ ' test. A probability values less than $0.05(p<0.05)$ was defined to be significant.

\section{Results and Discussions}

In this study, we have chosen $\mathrm{Cu}(\mathrm{II})$ and $\mathrm{Cr}(\mathrm{III})$ as intercalating metals with metronidazole and mebendazole, since copper and chromium are essential trace elements and traces are present in various foods. Copper could facilitate iron absorption and stimulate enzymes that are involved in the heme and/or globin biosynthesis pathways [16]. On the other hand, chromium was found necessary for optimal growth of experimental animals, in larger quantities it is toxic [17]. In addition we also take multivitamins and minerals preparations containing copper and chromium.

In spectral observation analysis, each of the drugs studied showed absorption in UVVIS region. The initial detection of complexation on metronidazole and mebendazole with $\mathrm{Cu}(\mathrm{II})$ and $\mathrm{Cr}(\mathrm{III})$ ions was done from the nature of the spectra of pure compounds as well as their 1:1 mixtures in different buffer solutions at fixed concentration $\left(1 \times 10^{-4} \mathrm{M}\right)$. Metronidazole gave a sharp peak at $328 \mathrm{~nm}$ and a valley at $267 \mathrm{~nm}$ at $\mathrm{pH}$ 2.4, 6.4 and 7.4. The peak intensities decreases at $\mathrm{pH}$ 2.4. Whereas, it gave a sharp peak at $277 \mathrm{~nm}$ and a valley at $245 \mathrm{~nm}$ at $\mathrm{pH} 0.8$ and 1.4. When $\mathrm{Cu}(\mathrm{II})$ and $\mathrm{Cr}(\mathrm{III})$ were mixed with metronidazole in 1:1 ratio, the intensities of peaks of metronidazole change remarkably i.e absorption characteristics are altered due to interaction but the $\lambda_{\max }$ remained unchanged. (Fig. 1a). This is may be due to the interaction between two compounds which may lead to form complex(es) having different light absorption capacity. A peak is observed at 212 nm due to the solvent ethanol.

On the other hand, mebendazole gave a sharp peak at $290 \mathrm{~nm}$ and a valley at $264 \mathrm{~nm}$ at $\mathrm{pH} 0.8,1.4$ and 2.4. But when mixed with $\mathrm{Cu}(\mathrm{II})$ and $\mathrm{Cr}(\mathrm{III})$ in $1: 1$ ratio the intensity of 
these peaks changed remarkably due to the interaction with metals (Fig. 2b). A peak is observed at $212 \mathrm{~nm}$ due to the solvent acetic acid.
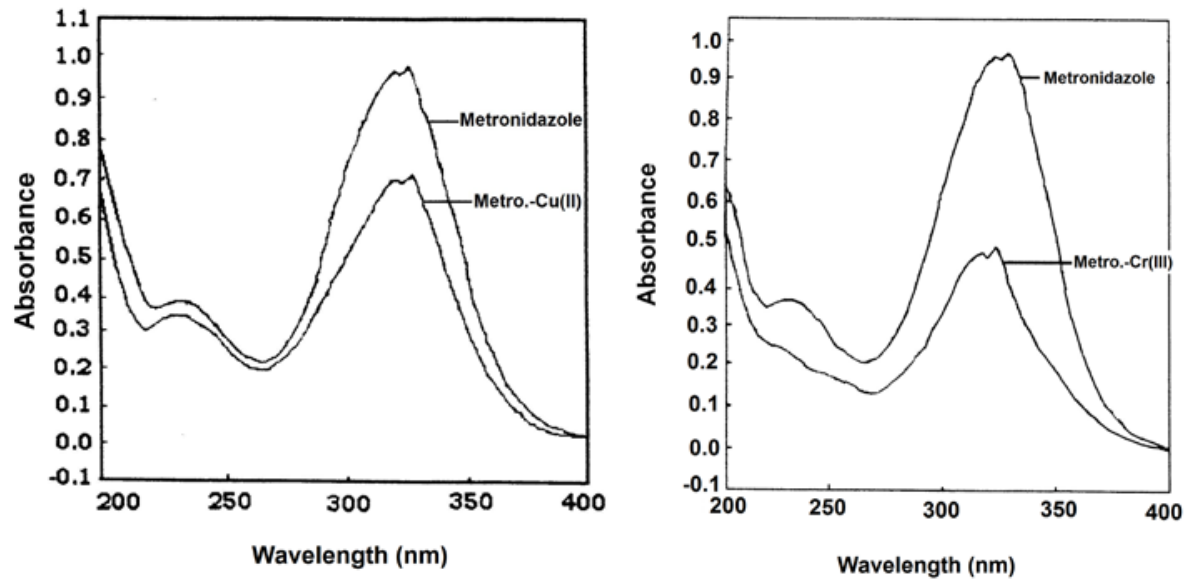

Fig. 1a. Influence of $\mathrm{Cu}(\mathrm{II})$ and $\mathrm{Cr}(\mathrm{III})$ on metronidazole at $\mathrm{pH}$ 7.4.
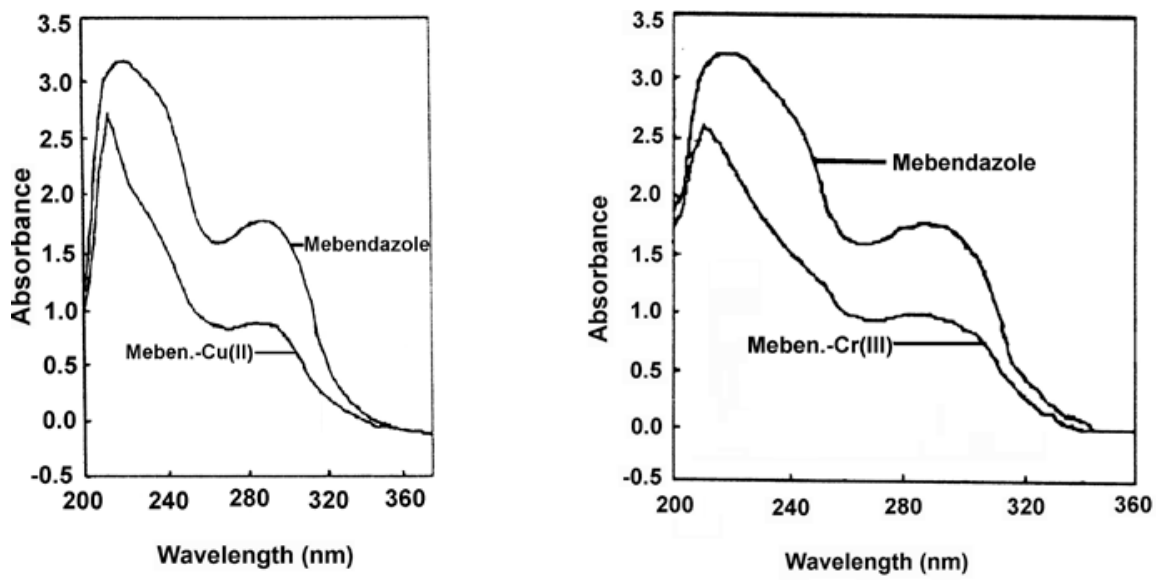

Fig. 1b. Influence of $\mathrm{Cu}(\mathrm{II})$ and $\mathrm{Cr}(\mathrm{III})$ on mebendazole at $\mathrm{pH} 1.4$.

Conductometric measurement in ethanol-deionized water showed that both the drug molecules interact with $\mathrm{Cu}(\mathrm{II})$ and $\mathrm{Cr}(\mathrm{III})$ ions at various molar ratios including 1:1. This is a proof of complex formation of the drug molecules with the metal ions [18]. When metronidazole solution was titrated with $\mathrm{Cu}(\mathrm{II})$ it showed two distinct breaks at ratios 2:3 and 1:4 and reverse titration gave break at ratios $1: 1$ and 7:2. This indicate that metronidazole form stable complex with $\mathrm{Cu}(\mathrm{II})$ at 1:1 molar ratio and unstable complexes or intermediates at ratio $1: 4$ and 7:2. When metronidazole solution was titrated with 
$\mathrm{Cr}$ (III) it showed one distinct break at ratios 2:3 and reverse titration gave two breaks at ratios 5:6 and 2:9 (Fig. 2a, b). This indicates that metronidazole form less stable complex with $\mathrm{Cr}(\mathrm{III})$ ion at 1:1 molar ratio and unstable complex or intermediate at 2:9.
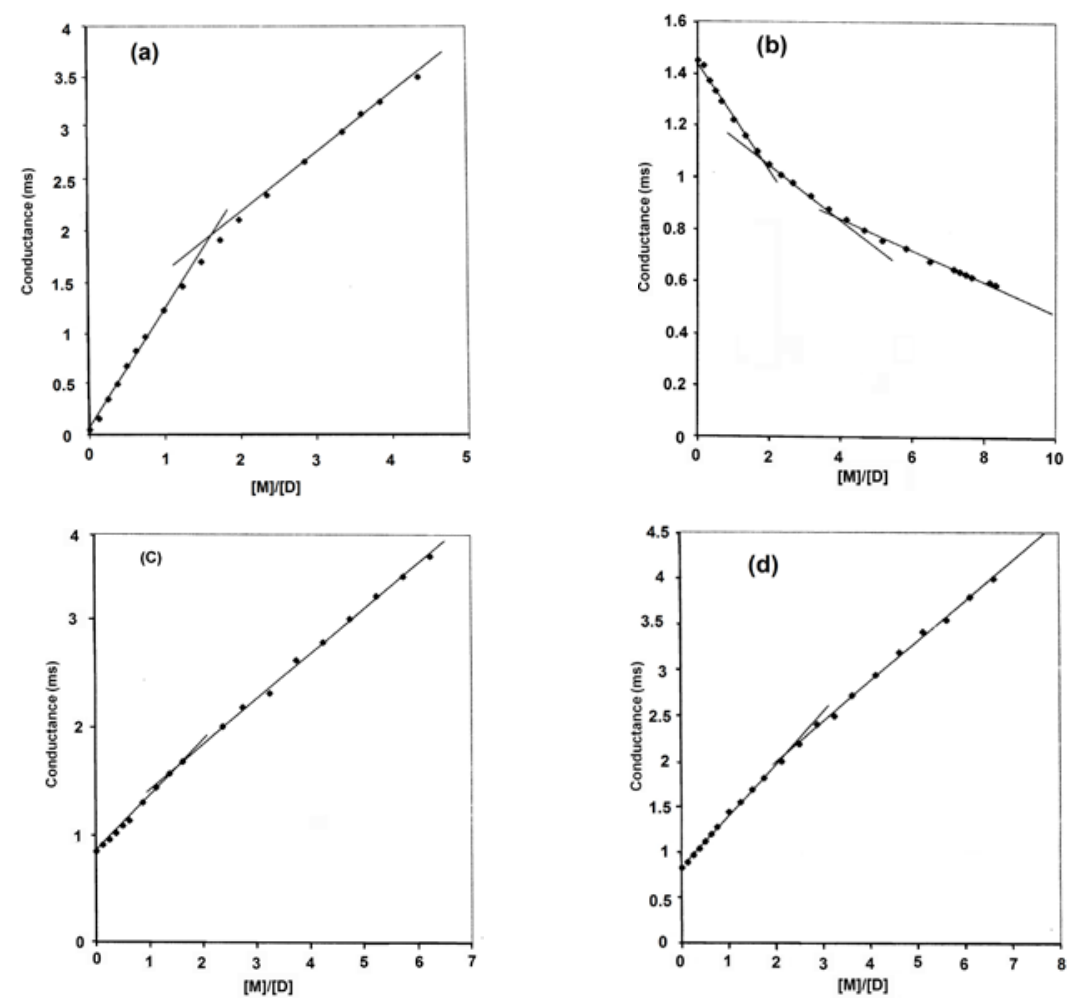

Fig. 2. Conductometric titration of metronidazole and mebendazole with $\mathrm{Cu}(\mathrm{II})$ and $\mathrm{Cr}(\mathrm{III})$; (a) metronidazole with $\mathrm{Cr}(\mathrm{III})$, (b) $\mathrm{Cr}(\mathrm{III})$ with metronidazole, (c) mebendazole with $\mathrm{Cu}(\mathrm{II})$, and (d) mebendazole with $\mathrm{Cr}(\mathrm{III})$.

But in the case of conductometric titration of mebendazole with $\mathrm{Cu}(\mathrm{II})$ and $\mathrm{Cr}$ (III) ions, no clear indication of interaction and formation of stable 1:1 complex was obtained, though formation of many intermediates were noticed. But the reverse mebendazole$\mathrm{Cu}(\mathrm{II})$ and mebendazole - $\mathrm{Cr}$ (III) system showed the formation of less stable 1:1 complex. When mebendazole solution was titrated with $\mathrm{Cu}(\mathrm{II})$ it showed one faint break at ratio 2:3 and reverse titration gave two distinct breaks at ratios 7:10, 31:10 and one faint break at ratio 8:5 (Fig. 2c). So, it can be inferred that the intermediates lead to 1:1 complex, which are seemed to be unstable. But when mebendazole solution was titrated with $\mathrm{Cr}$ (III) it showed one faint break at ratio 4:9. It appears that this complex is very unstable and the reverse titration gave three distinct breaks at ratios 1:5, 3:4 and 13:10 indicate that mebendazole form less stable complex with $\mathrm{Cr}(\mathrm{III})$ ion at 1:1 molar ratio and unstable complexes or intermediates at ratios 51:20 and 4:9 (Fig. 2d) . 
The molar ratios of the complexes of metronidazole and mebendazole with $\mathrm{Cu}(\mathrm{II})$ and $\mathrm{Cr}(\mathrm{III})$ ions were estimated by Job's spectroscopic methods of continuous variation. The Job's plots were obtained by plotting absorbance differences against the mole fraction of the each drugs. At, pH 2.4, metronidazole (Fig. 3a) and mebendazole (Fig. 3b) formed 1:1 stable complex with $\mathrm{Cr}$ (III) ion. On the other hand, mebendazole-Cu(II) formed 1:1 stable complex but metronidazole-Cu(II) formed 2:3 complex at $\mathrm{pH}$ 2.4.
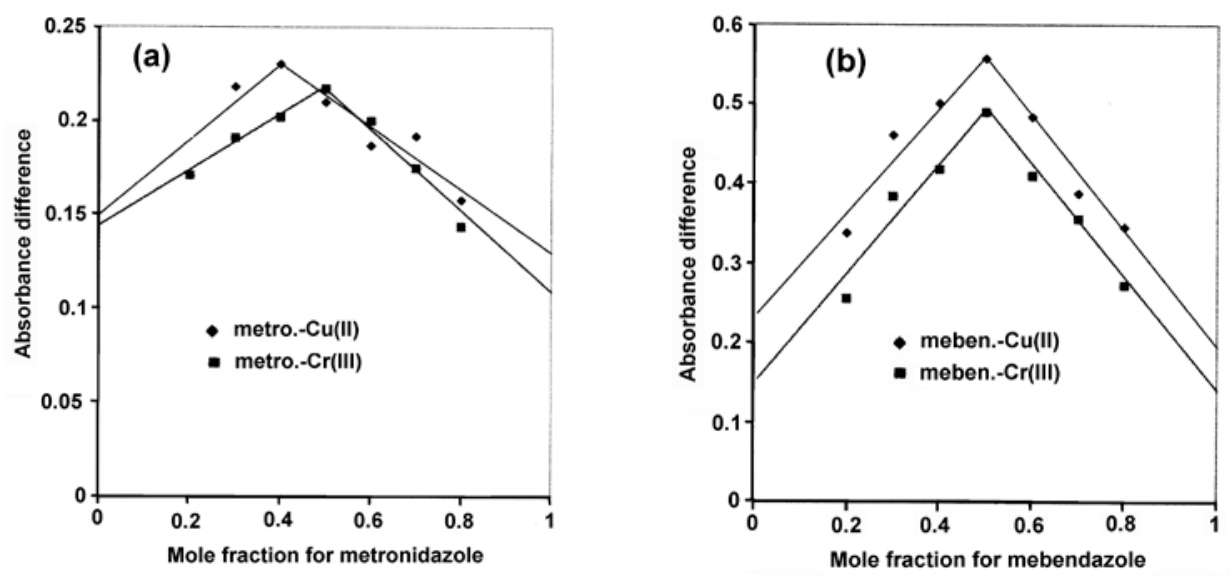

Fig. 3. Job’s plot for complexation. (a) metro.-Cu(II) \& metro.-Cr(III) at pH 6.4 and (b) meben.$\mathrm{Cu}(\mathrm{II})$ and meben.-Cr(III) at $\mathrm{pH} 2.4$.
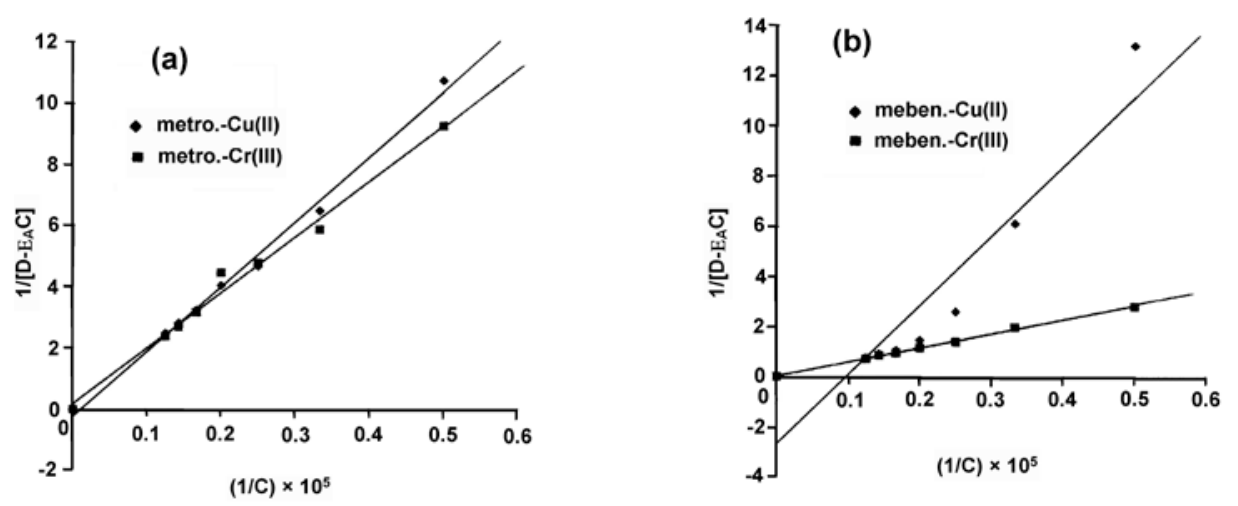

Fig. 4. Ardon's plot. (a) metro.-Cu(II) and metro.-Cr(III) at $\mathrm{pH} 2.4$ and (b) meben.-Cu(II) and meben.-Cr(III) at pH 2.4.

Ardon's plots confirmed the formation of 1:1 complexes of metronidazole and mebendazole with $\mathrm{Cu}(\mathrm{II})$ and $\mathrm{Cr}(\mathrm{III})$. The data for Ardon's plots was given straight lines with different intercepts, indicating the formation of 1:1 complexes for all systems. Stability constants for Metro.-Cu(II), Metro.-Cr(III), Meben.-Cu(II) and Meben.-Cr(III) 
systems were obtained from the Ardon's plots, which are straight lines. The stability constants were calculated from the slopes and intercepts of these plots and shown in Table 1. The Ardon's plots for Metro.-Cu(II), and Metro.-Cr(III) systems (Fig. 4a) and Meben.$\mathrm{Cu}(\mathrm{II})$ and Meben.-Cr(III) (Fig. 4b) are shown at $\mathrm{pH}$ 2.4.

Table 1 . The stability constants for different systems.

\begin{tabular}{cccccc}
\hline Systems & \multicolumn{5}{c}{ Stability constants (K x 10 $\left.0^{-2} / \mathrm{mole}\right)$} \\
\cline { 2 - 6 } & $\mathrm{pH} \mathrm{0.8}$ & $\mathrm{pH} 1.4$ & $\mathrm{pH} \mathrm{2.4}$ & $\mathrm{pH} \mathrm{6.4}$ & $\mathrm{pH} \mathrm{7.4}$ \\
\hline Metro. + Cu(II) & 1.7 & 3.59 & 0.99 & 0.62 & 4.28 \\
Metro. + Cr(II) & 0.296 & 0.164 & 1.1 & 4.21 & 0.78 \\
Meben. + Cu(II) & 0.293 & 0.35 & 0.4 & - & \\
Meben. + Cr(III) & 2.156 & 1.31 & 9.64 & - & \\
\hline
\end{tabular}

The stability constants obtained from the Ardon's plot shows that Metro.-Cu(II) system forms stable complex at $\mathrm{pH} 1.4$ and $\mathrm{pH}$ 7.4. But, Metro.-Cr(III) forms stable complex at $\mathrm{pH} 6.4$ having high stability constants. On the other hand, the stability constant for meben.-Cr(III) system is higher than all other systems at all $\mathrm{pH}$ values. So, we can conclude that metronidazole forms stable complex with both $\mathrm{Cu}(\mathrm{II})$ and $\mathrm{Cr}(\mathrm{III})$. However, mebendazole forms stable complex with $\mathrm{Cr}(\mathrm{III})$ ion and less stable complex with $\mathrm{Cu}(\mathrm{II})$ ion at lower $\mathrm{pH}$. An inspection of the structures of the two ligands also indicate the justification of these observations.

\section{Conclusion}

It has been observed that the stability constants for metro.-Cu(II) system and metro-Cr(III) systems at higher $\mathrm{pH}$ were higher than that of metro.-Cu(II) system and metro.-Cr(III) system at lower $\mathrm{pH}$ conditions, indicating a weak complexation at a lower $\mathrm{pH}$. Again, it was also observed that, complexation between metro-Cr(III) system at lower $\mathrm{pH}$ is too weak than metro.-Cu(II) system. The stability constant for meben.-Cr(III) system at lower $\mathrm{pH}$ was higher than that of meben.-Cu(II) system, indicating a stable 1:1 complexation between meben.-Cr(III) at lower $\mathrm{pH}$.

\section{References}

1. A. E. Martell and R.M. Smith, Critical Stability Constants (First Supplement Press, NY, USA, 1982).

2. S. Botton and R. I. Ellin, J. Pharm. Sci. 51, 533 (1962). http://dx.doi.org/10.1002/jps.2600510609

3. P. D. Hansten and J. R. Horn, Drug Interactions: Clinical Significance of Drug-drug Interaction, 6th ed. (Philadelphia, 1989).

4. A. Martin, S. James and C. Arthur, Physical Pharmacy, Lea and Febiger, 3rd ed. (Philadelphia, USA, 1993) pp. 341-342. 
5. S. Z. Haider, Introduction to Modern Inorganic Chemistry, 5th ed. (Students publication, Dhaka, Bangladesh, 1977) pp. 98, 278, 638, 653.

6. S. Z. Haider and K. M. A. Malik, J. Bang. Acad. Sci. 2, 117 (1987).

7. M. S. Amran, M. A. Baki and M. A. Hossain, In vitro and in vivo effects of glipizide and gliclazide on the protein binding and plasma concentration of ibuprofen. Presented at $31^{\text {st }}$ Annual Conference of Bangladesh Chemical Society, University of Dhaka, Dhaka, Bangladesh (2009).

8. M. S. Amran, S. N. Morshed, M. J. A. Khandakar, M. M. Rahman, and M. A. Hossain, Dhaka Univ. J. Pharm. Sci. 7, 15 (2008).

9. M. S. Amran, A. H. M. R. Bari, and M. A. Hossain, Dhaka Univ. J. Pharm. Sci. 5, 25 (2006).

10. M. S. Amran, M. M. Rahatuzzamn, and M. A. Hossain, J. Bio. Sci. 14, 61 (2006).

11. M. S. Amran and M. A. Hossain, Rajshahi Univ. Studies, Part B. 26, 35 (1999).

12. A. H. M. R. Bari, A.T .M. Z. Azam, M. S. Amran, and M. A. Hossain, Pak. J. Biol. Sci. 3 (4), 555 (2000).

13. S. C. Sweetman, Martindale: The Complete Drug Reference. 34th ed. (Pharmaceutical Press, London, 2005).

14. A. I. Vogel, A Textbook of Quantitative Inorganic Analysis. 3rd ed. (Longmans, London, 1961) p. 93.

15. M. Ardon, J. Chem. Soc. 1811 (1957). http://dx.doi.org/10.1039/jr9570001811

16. H. B. John, B. R. Edward, O. W. Charles and O. S. Taito, Inorganic Medicinal and Pharmaceutical Chemistry (Henry Kimpton, London, 1974) p. 213.

17. B. Pal and J. Mukherjee. J. Appl. Nutr. 30, 14 (1978).

18. S. N. Nabi, A. Hussain and N. N. Ahmed. J. Chem. Soc., Dalton Trans. 1199 (1974). http://dx.doi.org/10.1039/dt9740001199 